\title{
Características físico-quimicas, análise sensorial e conservação de frutos de cultivares de bananeira resistentes à sigatoca-negra ${ }^{1}$
}

\author{
Célia Lúcia Siqueira², Maria Luisa Mendes Rodrigues³, Gisele Polete Mizobutsi ${ }^{4}$, Paulo Gomes dos Santos², \\ Wagner Ferreira da Mota ${ }^{3}$, Edson Hiydu Mizobutsi ${ }^{3}$, Gildete Bispo de Oliveira ${ }^{5}$
}

\section{RESUMO}

O cultivar Prata Anã é o mais plantada no Norte de Minas Gerais, o que demonstra estar a bananicultura regional baseada numa variedade suscetível à sigatoca-negra. Apesar de existirem cultivares resistentes em fase de recomendação para o cultivo na região, ainda são escassos os trabalhos relacionados a metodologias de conservação pós-colheita. Assim, o objetivo deste trabalho foi avaliar o período de armazenamento e as características físico-químicas e sensoriais dos cultivares de bananeira Fhia - 02 e Precioso, ambos resistentes à sigatoca-negra, e o efeito da atmosfera modificada associada à refrigeração. Foram realizados três experimentos, o primeiro em temperatura ambiente, o segundo a $12{ }^{\circ} \mathrm{C} e$ o terceiro a $15{ }^{\circ} \mathrm{C}$. Esses experimentos foram instalados no delineamento em blocos casualizados em esquema de parcelas subdivididas no tempo, tendo nas parcelas um fatorial 2 (com e sem embalagem) x 2 (Fhia - 02 e Precioso) e nas subparcelas as avaliações em intervalo de seis e dois dias para frutos armazenados nas temperaturas de 12,15 e $25^{\circ} \mathrm{C}$, com quatro repetições e três frutos por unidade experimental. Após o tratamento, os frutos foram dispostos em bandejas de poliestireno expandido (sem embalagem) e embalagens de 10 e $16 \mu \mathrm{m}$ e umidade relativa de $90 \%$. As características avaliadas foram: tamanho, diâmetro, cor, firmeza, perda de matéria fresca, sólidos solúveis totais (SST), acidez total titulável (ATT), SST/ATT, pH e análise sensorial. O uso da embalagem associada à refrigeração permitiu armazenar os frutos por 28 dias, mantendo as características físico-químicas.

Palavras-chave: Musa ssp, refrigeração, polietileno de baixa densidade e Mycosphaerella fijiensis Morelet.

\section{ABSTRACT}

\section{Physiochemical characteristics, sensorial analysis and fruit conservation of a black Sigatoka- resistant banana genotype}

The cultivar Prata Anã is widely grown in the North of Minas Gerais State, Brazil, hence, the banana business in the region is based on a variety susceptible to Black Sigatoka. Although there are resistant cultivars being recommended to cultivation in the region, studies related to post-harvest conservation are still scarce. The objective of the present work was to evaluate the storage period and physiochemical and sensorial characteristics of cultivars, Fhia - 02 and Preciosa, both resistant to Black Sigatoka, and the effect of the modified atmosphere associated with cooling. Three experiments were carried out, the first under ambient temperature, the second at $12^{\circ} \mathrm{C}$ and the third at $15^{\circ} \mathrm{C}$, The experiments were arranged in randomized block design with split-plots in the time, having in the plots a 2x2 factorial

Recebido para publicação em fevereiro de 2008 e aprovado em setembro de 2009

${ }^{1}$ Trabalho extraído da dissertação de Mestrado em Produção Vegetal no Semi- Árido e financiado pela Fapemig.

${ }^{2}$ Engenheira-Agrônoma, Mestre. Departamento de Ciências Agrárias da Unimontes, Unimontes. Rua dos Bandeirantes, 525, São Gonçalo, 39.440-000, Janaúba, Minas Gerais, Brasil. clsiq@emater.mg.gov.br.

${ }^{3}$ Engenheira-Agrônoma. Departamento de Ciências Agrárias da Unimontes, Unimontes Avenida Reinaldo Viana, 2630, Bico da Pedra, 39440-000, Janaúba, Minas Gerais, Brasil. marialuisamendes@yahoo.com.br

${ }^{4}$ Engenheiro-Agrônomo. Departamento de Ciências Agrárias da Unimontes, Unimontes Avenida Reinaldo Viana, 2630, Bico da Pedra, 39440-000, Janaúba, Minas Gerais, Brasil. giselle.mizobutsi@unimontes.br

${ }^{5}$ Engenheiro-Agrônomo. Pesquisador da EMATER/Minas Gerais. Rua Dezessete, 02, Mocambinho, 39.508-000, Jaíba, Minas Gerais, Brasil. gildetebispo@emater.mg.gov.br 
(with and without packing) $\mathrm{x}$ (Fhia - 02 and Preciosa), and in the subplots the evaluations at six and two days, at 12, 15 and $25^{\circ} \mathrm{C}$, with four repetitions and three fruits per experimental unit. After the treatment, the fruits were placed in expanded polystyrene trays (without packaging) and $10 \mu \mathrm{m}$ and $16 \mu \mathrm{m}$ packagings and relative humidity of $90 \%$. The evaluated characteristics were size, diameter, color, firmness, loss of fresh matter, total soluble solids (TSS), total titratable acidity (TTA), TSS/TTA, pH and sensorial analysis. The use of packaging associated with cooling allowed fruit storage for 28 days keeping its physical-chemical characteristics.

Key words: Cooling, low density polyethylene, Mycospharella fijiensis Morelet, Musa ssp.

\section{INTRODUÇÃO}

A região Norte de Minas Gerais vem despontando como grande pólo frutícola do Brasil, sendo a cultura da banana a principal atividade agrícola, ocupando atualmente 5.990 ha, considerando-se somente os perímetros irrigados. Estima-se que a área total ocupada pela cultura da bananeira seja em torno de 10 mil hectares, e cerca de 90\% dessa área é cultivada com a Prata Anã (Rodrigues et al., 2001).

De acordo com a Codevasf (2005), no Norte de Minas Gerais obteve-se uma produção global acima de 32 mil toneladas (equivalente a 225 cargas de caminhão por semana; ou ainda, 32 cargas por dia), com uma receita para os produtores de nove milhões de reais. No aspecto social, os projetos de irrigação geram 12.200 empregos diretos e 24.400 indiretos.

O Norte de Minas Gerais apresenta condições edafoclimáticas ideais para a exploração da bananicultura, entretanto, os problemas fitossanitários constituem a maior ameaça, tendo em vista a utilização generalizada dos cultivares Prata, suscetíveis à sigatoca-negra (Mycosphaerella fijiensis Morelet) (Ledo et al., 1997). A sigatoca-negra está disseminada em toda América Central e em algumas regiões da África, Ásia e América do Sul. A doença foi constatada na Colômbia, Venezuela, no Equador e, atualmente, está disseminada também em estados das regiões Sul e Sudeste do Brasil (Cordeiro et al., 2005). O controle genético, por meio da utilização de variedades e híbridos resistentes e/ou tolerantes à doença, tem sido a alternativa adotada para minimizar os prejuízos e evitar a disseminação da doença para outras regiões produtoras do Brasil, como o pólo frutícola do norte mineiro, cuja economia regional está sustentada no arranjo produtivo da bananicultura. Entretanto, ainda não foram recomendados cultivares adaptados às condições edafoclimáticas do Norte de Minas Gerais, e uma de suas razões reside no desconhecimento das características de armazenamento pós-colheita dos novos cultivares.

As perdas pós-colheita podem ter causas diversas, dentre as quais se destacam as doenças. Chitarra \& Chitarra (2005) afirmam que as perdas brasileiras em ba- nanas podem chegar a $30 \%$ do total produzido; e os fungos são responsáveis por 80 a 90\% das perdas causadas por fitopatógenos. Com a grande possibilidade da introdução da Sigatoca-negra na região e os seus consequentes prejuízos econômicos, é fundamental o desenvolvimento de tecnologia de cultivo e pós-colheita referente a híbridos e variedades novas resistentes a essa praga, pois o plantio desses cultivares constituirá uma das principais medidas de controle a serem adotadas pelos produtores.

A manutenção da qualidade dos produtos hortifrutícolas deve-se às técnicas de armazenamento pós-colheita que reduzem as taxas respiratórias, retardam o amadurecimento e previnem as desordens fisiológicas dos frutos. A banana é um fruto climatérico, por isso amadurece rapidamente em altas temperaturas e sua vida de prateleira é curta. $\mathrm{O}$ amadurecimento caracteriza-se por uma série de transformações no fruto, marcadamente mudanças na coloração da casca (degradação da clorofila) e na firmeza da polpa, além da intensificação do sabor e aroma pela produção de voláteis (Chitarra \& Chitarra, 2005).

Atualmente, não existem trabalhos a respeito da época de colheita e metodologias de conservação dos frutos da bananeira, bem como as análises sensoriais (aceitação do produto pelo consumidor), físico-química e nutricional desses novos materiais resistentes à sigatoca-negra.

Dessa forma, este trabalho teve por objetivo avaliar o período de armazenamento, as características físico-químicas e sensoriais e o efeito da atmosfera modificada associada ao uso de refrigeração na conservação de frutos de dois cultivares de bananeira resistentes à sigatoca-negra.

\section{MATERIAL E MÉTODOS}

Os frutos foram colhidos na fazenda experimental da Epamig, localizada em Mocambinho, município de JaíbaMG no estádio pré-climatérico. O trabalho foi realizado no Laboratório de Pós-Colheita de Frutos do Departamento de Ciências Agrárias da Universidade Estadual de Montes Claros (Unimontes), Janaúba - MG. Utilizaram-se os 
cultivares de bananeira Fhia - 02, tetraplóide (AAAA) e Precioso (PV4285), tetraplóide (AAAB), ambos resistentes à sigatoca-negra (Silva et al., 2002).

Selecionaram-se pencas de bananas de cachos colhidos aleatoriamente, no índice de coloração dois, descrito na escala de cores de Dadzie \& Orchard (1997). Após a despenca, os frutos foram lavados com água e sabão, posteriormente imersos por cinco minutos em 15 litros de suspensão do fungicida pós-colheita Sportak (Procloraz), na concentração de 125 ppm e espalhante adesivo Iharaguem na concentração de 0,3 ppm. Em seguida, as pencas foram divididas em buquês de três frutos, e esses, selecionados, embalados com membrana MN860 (16 $\mu \mathrm{m})$ e MV760 $(10 \mu \mathrm{m})$ e sem embalagem em bandejas de poliestireno expandido e acondicionados em câmaras frias com temperaturas de 12 , 15 e $25^{\circ} \mathrm{C}$. As avaliações foram realizadas com intervalos de dois dias na temperatura de $25^{\circ} \mathrm{C}$ durante um período de 12 dias e de seis dias para as temperaturas de 12 e $15^{\circ} \mathrm{C}$ por um período de 28 dias e umidade relativa de $90 \%$.

Foram realizados três experimentos, o primeiro em temperatura a $25^{\circ} \mathrm{C}$, simulando o ambiente, o segundo a $12^{\circ} \mathrm{C}$ e o terceiro a $15^{\circ} \mathrm{C}$. Esses experimentos foram instalados no delineamento em blocos casualizados em esquema de parcelas subdivididas no tempo, tendo nas parcelas um

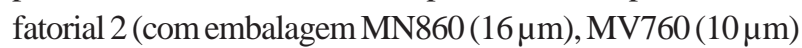
e sem embalagem) x 2 (Fhia - 02 e Precioso). Nas subparcelas as avaliações em intervalo de seis dias para frutos armazenados nas temperaturas de 12 e $15^{\circ} \mathrm{C}$ e dois dias para temperatura de $25^{\circ} \mathrm{C}$, utilizaram-se quatro repetições e três frutos por unidade experimental. A fim de simular o período de conservação pós-colheita, os parâmetros físico-químicos avaliados foram: a) Firmeza: determinada pela força de penetração, medida em Newton $(\mathrm{N})$, necessária para que a agulha de $2,5 \mathrm{~cm}$ de comprimento e $0,8 \mathrm{~cm}$ de diâmetro penetre na polpa do fruto. Foi utilizado um penetrômetro de mão marca FACCHINI, modelo FT 011; b) Sólidos solúveis totais (SST): utilizandose um refratômetro de campo da marca ATAGO, modelo $\mathrm{N}$ - 1á, com leitura na faixa de 0 a $95^{\circ}$ Brix, e o resultado expresso em ${ }^{\circ}$ Brix; c) Acidez total titulável (ATT): foi determinada por meio da titulação de 10 gramas de polpa triturada e homogeneizada com $90 \mathrm{~mL}$ de água destilada. Utilizou-se como titulante solução de $\mathrm{NaOH} 0,1 \mathrm{~N}$, adicionando à amostra três gotas de fenolftaleína a $1 \%$ como indicador. Os resultados foram expressos em eq. mg. Ácido Málico por 100 gramas de polpa, de acordo com as normas da Association of Official Analytical Chemists AOAC (1992); de pH: foi realizada a determinação do pH utilizando-se 10 gramas de polpa triturada e homogeneizada com $90 \mathrm{~mL}$ de água destilada. A leitura foi realizada utilizando-se peagômetro Digital da marca Digimed, modelo DM20; e) Cor: essa análise foi feita utilizando-se a escala de Loesecke (1980): (1) totalmente verde, (2) verde clara, (3) $50 \%$ verde e $50 \%$ amarela, (4) mais amarela que verde, (5) amarela com pontas verdes, (6) totalmente amarela e (7) amarela com manchas marrons; f) Comprimento e diâmetro do fruto: foram obtidos com a utilização de um paquímetro, no qual foram estimados o comprimento e diâmetro médio dos frutos, e os resultados foram expressos em centímetros; g) Perda de matéria fresca do fruto: os frutos foram pesados individualmente, o resultado da perda de matéria fresca em relação à massa inicial foi expresso em porcentagem; h) Relação sólidos solúveis totais/acidez titulável: dividiu-se a porcentagem de sólidos solúveis totais pela acidez titulável; i) Análise sensorial: foi determinada através de degustação. Um grupo de 30 pessoas por dia, em que cada provador constituía um bloco experimental casualizado, foi submetido à análise sensorial. Cada membro do grupo deu nota de 1 (desgostei extremamente), 2( gostei moderadamente), 3 (indiferente), 4 (desgostei ligeiramente) e 5 (gostei extremamente).

Os dados foram submetidos à análise de variância e de regressão. As médias dos fatores qualitativos foram comparadas, utilizando-se o teste de Tukey a 5\% de probabilidade. Para os fatores quantitativos, os modelos de regressão foram escolhidos com base na significância dos coeficientes de regressão, utilizando-se o teste $t$ de Student a 5\% de probabilidade no coeficiente de determinação e no potencial para explicar o fenômeno biológico.

\section{RESULTADOS E DISCUSSÃO}

De acordo com as análises constata-se diferenças significativas entre os cultivares para as características comprimento e diâmetro, com maiores valores para o cultivar Precioso quando comparado ao Fhia -02 (Tabela I).

Durante o período de avaliação, constatou-se a interferência da embalagem nas porcentagens das perdas de massa fresca dos frutos (Figura 1). As maiores perdas, verificadas nos frutos-controle armazenados a $25^{\circ} \mathrm{C}$, chegaram a aproximadamente $18 \%$ aos 12 dias de armazenamento, e os frutos armazenados com embalagem de 10 e 16 $\mu \mathrm{m}$ as perdas foram de $2 \%$. A embalagem, aliada à refrigeração, influiu significativamente na redução da perda de matéria fresca dos frutos, tendo os frutos armazenados a $12^{\circ} \mathrm{C}$ apresentado perda de 20, 1 e 1\% para os frutos armazenados sem embalagem e embalados a 10 e $16 \mu \mathrm{m}$, respectiva-

Tabela 1. Análise de comprimento e diâmetro dos cultivares de bananeira Fhia - 02 e Precioso cultivados e avaliados na Região Norte de Minas Gerais usando como método o paquímetro e a unidade de medida o centímetro

\begin{tabular}{lc}
\hline Fhia - 02 & Precioso \\
\hline Comprimento $(\mathrm{cm})-17$ & Diâmetro $(\mathrm{cm})-4,0$ \\
Comprimento $(\mathrm{cm})-20$ & Diâmetro $(\mathrm{cm})-4,5$ \\
\hline
\end{tabular}

Rev. Ceres, Viçosa, v. 57, n.5, p. 673-678, set/out, 2010 


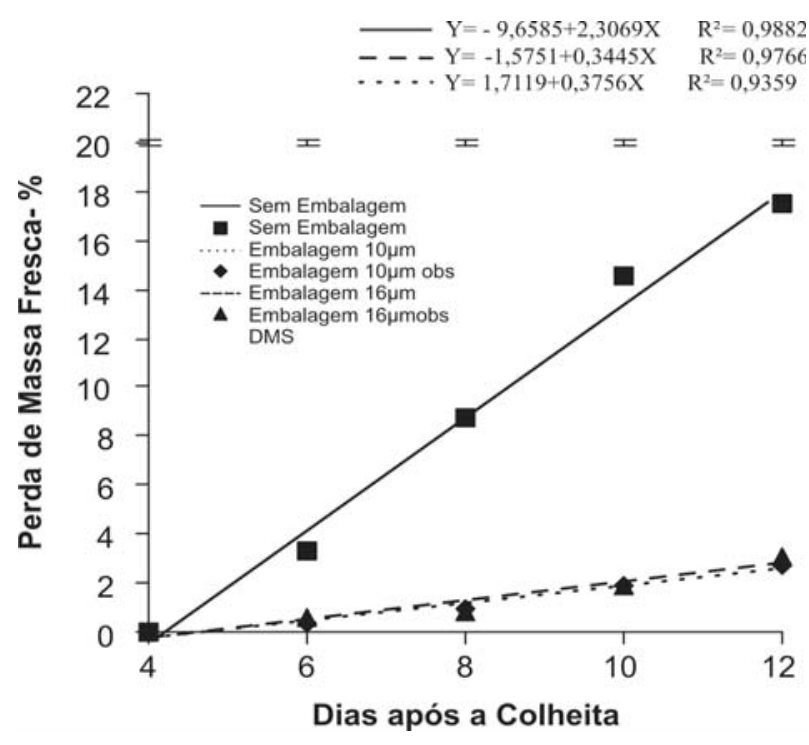

Figura 1. Perda de massa fresca dos frutos dos cultivares de bananeira Fhia - 02 e Precioso. Armazenados a $25{ }^{\circ} \mathrm{C}$, sem embalagem (SE) e com embalagem de 10 e $16 \mu$ m durante 12 dias, nas condições do Norte de Minas.

mente. O mesmo ocorreu para os frutos armazenados a 15 ${ }^{\circ} \mathrm{C}$, esses tiveram perda de matéria fresca de 19, 1 e $2 \%$ para os frutos armazenados sem embalagem e embalados a $10 \mathrm{e}$ $16 \mu \mathrm{m}$, respectivamente. A redução na perda de massa fresca observada nos frutos em atmosfera modificada, possivelmente, seja decorrente do aumento da umidade relativa do ar no interior das embalagens, que satura a atmosfera ao redor dos frutos, leva à diminuição do déficit de pressão de vapor d'água e, consequentemente, reduz a transpiração dos frutos (Kader et al., 1989).

A embalagem influenciou significativamente no desenvolvimento da coloração dos frutos. Pode-se verificar que nos frutos armazenados a 25,12 e $15^{\circ} \mathrm{C}$ sem embalagem, independentemente da variedade, houve evolução na coloração, demonstrando, prematuramente, avançado estádio de amadurecimento. Esse comportamento, segundo alguns autores (Souza et al., 2002; Neves et al., 2002; Yamashita et al., 2002), pode ser explicado pelo fato de que quando os frutos foram armazenados sem embalagem aumentou a velocidade do seu metabolismo, acelerando o amadurecimento. No entanto, os frutos acondicionados em atmosfera modificada, associados à refrigeração (12 e $15^{\circ} \mathrm{C}$ ), apresentaram coloração 50\% amarelada e, aparentemente, em estádio menos avançado de amadurecimento que os dos demais tratamentos (Figura 2). Assim, pressupõe-se um aumento no período seguro de comercialização, com adequada manutenção da qualidade desses frutos.

Detectou-se decréscimo da firmeza da polpa ao longo do período experimental, constatando diferença significativa entre os frutos com e sem embalagem, tendo os frutos- controle apresentado as maiores perdas. Esses frutos, aos 12 dias de armazenamento a $25^{\circ} \mathrm{C}$, já apresenta- vam firmeza bem abaixo dos demais tratamentos, com valores não mensuráveis pelo método de análise utilizado. A simples manutenção da atmosfera refrigerada, sem a utilização da embalagem, não foi suficiente para controlar a drástica diminuição da firmeza. A melhor manutenção dos valores de firmeza foi observada nos frutos acondicionados nas embalagens de 10 e $16 \mu \mathrm{m}$ e associado à temperatura de 12 e $15^{\circ} \mathrm{C}$ (Figura 3). Tal fato, segundo Kader et al. (1989) e Kader (1992), ocorre pela correta associação entre o tipo de fruto e a espessura do filme de polietileno utilizado. A elevação dos níveis de $\mathrm{CO}_{2}$ e a diminuição dos

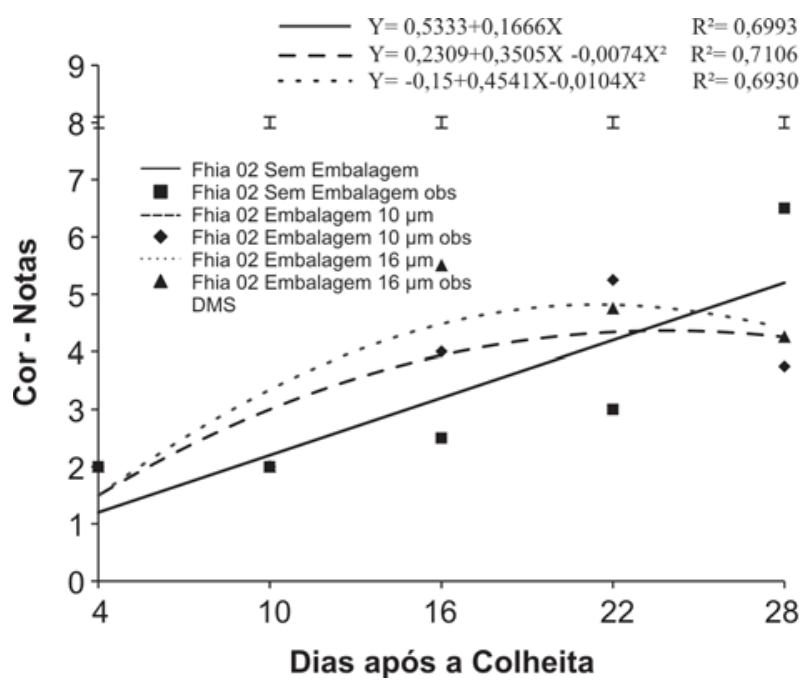

Figura 2. Coloração do pericarpo dos frutos do cultivar de bananeira Fhia - 02, armazenados a $12^{\circ} \mathrm{C}$ sem embalagem (SE) e com embalagem de 10 e $16 \mu \mathrm{m}$ durante 28 dias, nas condições do Norte de Minas.

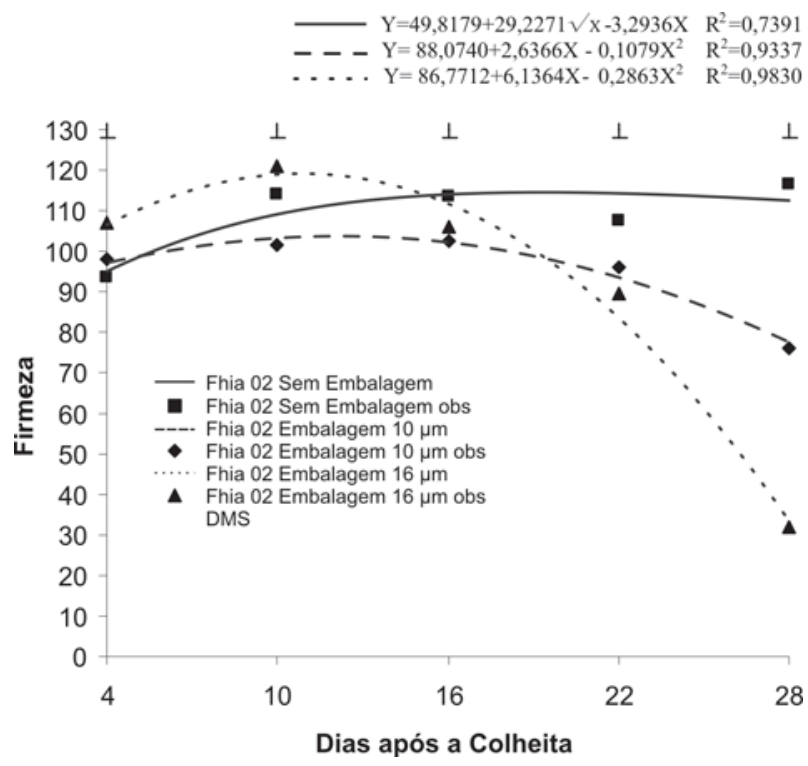

Figura 3. Firmeza do pericarpo de frutos do cultivar de bananeira Fhia - 02 armazenados a $12{ }^{\circ} \mathrm{C}$ sem embalagem (SE) e com embalagem de 10 e $16 \mu \mathrm{m}$, durante 28 dias, nas condições do Norte de Minas Gerais. 
níveis de $\mathrm{O}_{2}$, por meio do uso de embalagens plásticas, até concentrações não-prejudiciais preservam a integridade dos tecidos celulares, possibilitando, entre outros fatores, a redução da taxa e da velocidade da perda de firmeza do fruto.

O teor de sólidos solúveis totais aumentou progressivamente em todos os frutos durante o período de avaliação. Os maiores incrementos foram detectados nos frutos armazenados sem embalagem, comprovando sua alta atividade metabólica em relação aos demais tratamentos. A embalagem de polietileno proporcionou contenção na velocidade do desenvolvimento dos teores de SST. Entretanto, neste experimento a razão para o incremento nos teores de SST, supostamente, foi a desidratação parcial destes frutos durante o período de amadurecimento, concentrando, portanto, o conteúdo celular. Os frutos acondicionados nas embalagens de 10 e $16 \mu \mathrm{m}$ apresentaram diminuição na velocidade do metabolismo, aparentando estádio menos avançado de amadurecimento (Figura 4). Esses dados são concordantes com Silva et al. (2006) e Souza et al. (2002), de que a diminuição na atividade metabólica dos frutos embalados se deve à modificação atmosférica no interior das embalagens, proporcionando contenção nos teores de SST.

A ATT das bananas, nos diferentes tratamentos, apresentou tendência de elevação no decorrer do experimento nos frutos armazenados a 25,12 e $15^{\circ} \mathrm{C}$, porém o que se pode verificar é que a elevação do teor de ATT foi mais

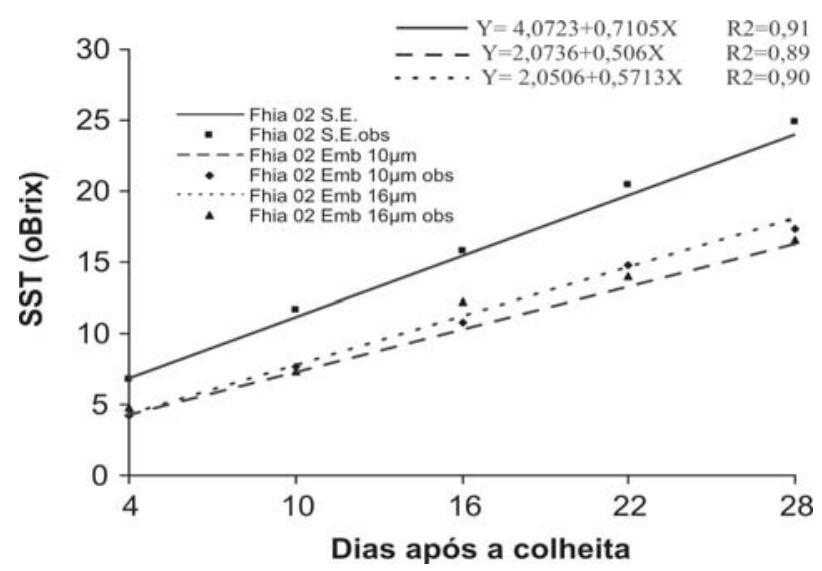

Figura 4. Teor de sólidos solúveis totais de frutos do culltivar PV 4285 armazenadas sem embalagem (SE) e com embalagem de 10 e $16 \mu \mathrm{m}$, durante 28 dias, nas condições do Norte de Minas. acentuada para os frutos-controle (Figura 5). De acordo com Carvalho et al. (1989) e Rocha (1984), a acidez titulável para a banana cresce com o seu amadurecimento e decresce quando a fruta se encontra muito madura ou senescente. No entanto, neste trabalho percebeu-se que esse aumento ocorreu de maneira menos acentuada nos frutos em atmosfera modificada. Esse comportamento indica que houve retenção no metabolismo de transformação dos ácidos orgânicos pelo uso das embalagens de 10 e $16 \mu \mathrm{m}$.

A relação SST/ATT dos frutos analisados durante o período estudado apresentou valores que variaram entre 18 e 65 (Figura 6).

Pode-se observar que o $\mathrm{pH}$ diminui à medida que avança a maturação dos frutos. Detectou-se o menor valor para os frutos armazenados sob refrigeração associados à atmosfera modificada e à superioridade do tratamento para os frutos-controle, o que caracteriza o pós-climatério, conforme detectado por Dominguez \& Vendrell (1993) ao construírem as curvas de mudanças na respiração e produção de etileno para bananas (Figura 7).

Ao final do experimento, os frutos acondicionados nas embalagens e associados à refrigeração apresentaram os melhores índices de preferência frente aos julgadores (Tabela II). Isso comprova que os melhores resultados obtidos nas análises físico-químicas convergem do mesmo tratamento escolhido pelos julgadores na análise sensorial, enquanto os frutos-controle, pelo adi-

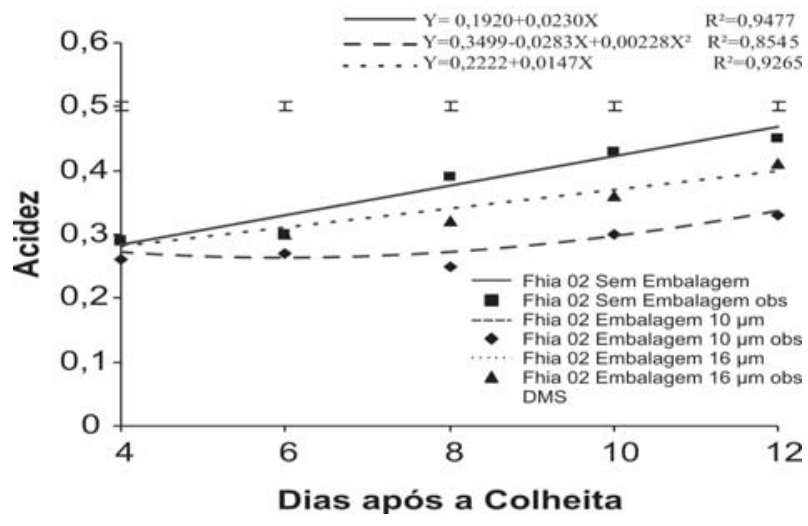

Figura 5. Acidez total titulável de frutos do cultivar de bananeira Fhia - 02 armazenados a $25{ }^{\circ} \mathrm{C}$ sem embalagem (SE) e com embalagem de 10 e $16 \mu \mathrm{m}$, durante 12 dias, nas condições do Norte de Minas.

Tabela 2. Análise sensorial dos cultivares de bananeira Fhia - 02 e Precioso nas condições do Norte de Minas Gerais

\begin{tabular}{ll}
\hline Fhia - 02 & \multicolumn{1}{c}{ Precioso } \\
\hline $6,66 \%$ - gostei extremamente & $20,0 \%$ - gostei extremamente \\
$50,00 \%$ - gostei moderadamente & $26,67 \%$ - gostei moderadamente \\
$16,67 \%$ - indiferente & $40,00 \%$ - indiferente \\
$10,00 \%$ - desgostei ligeiramente & $0,00 \%$ - desgostei ligeiramente \\
$16,67 \%$ - desgostei extremamente & $13,33 \%$ - desgostei extremamente \\
\hline
\end{tabular}




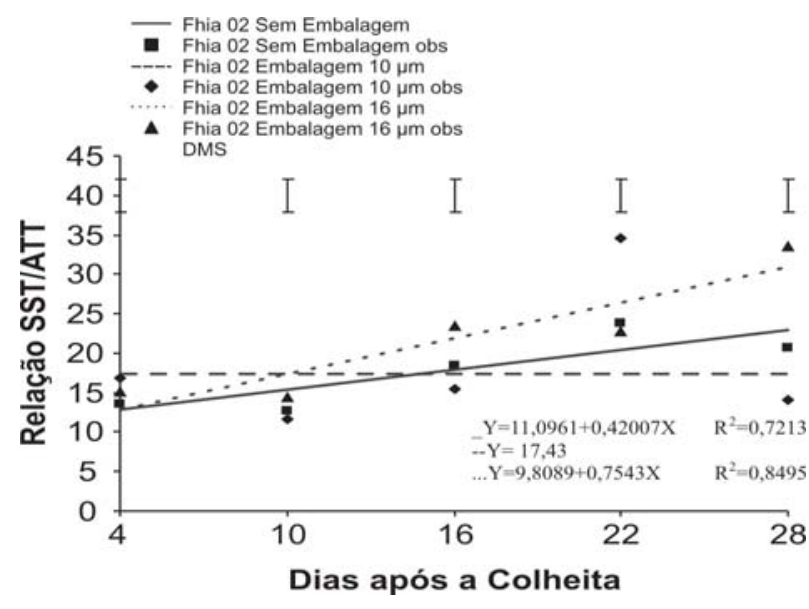

Figura 6. Relação SS/ATT de frutos de bananeira do cultivar Fhia 02 armazenados a $12{ }^{\circ} \mathrm{C}$ sem embalagem (SE) e com embalagem de 10 e $16 \mu \mathrm{m}$, durante 28 dias, nas condições do Norte de Minas.

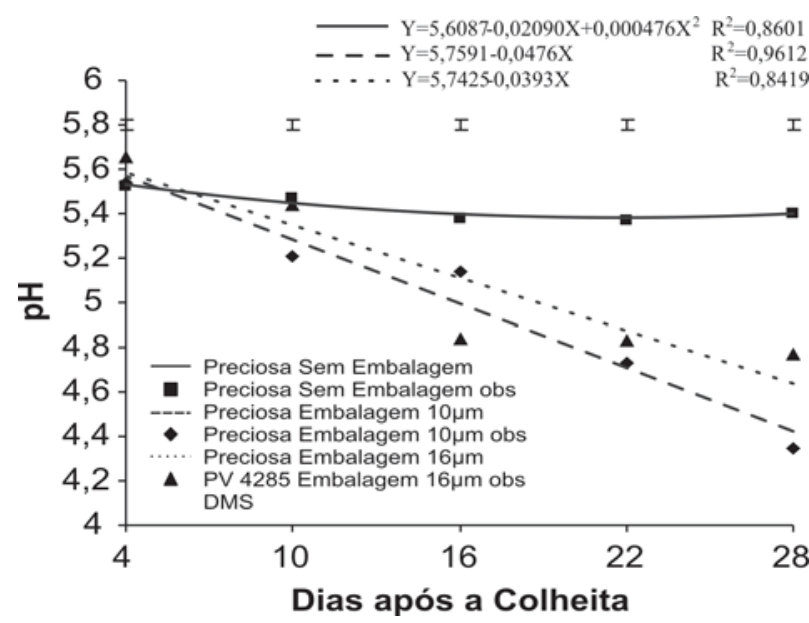

Figura 7. $\mathrm{pH}$ de frutos do cultivar de bananeira Preciosa armazenados a $15^{\circ} \mathrm{C}$ sem embalagem (SE) e com embalagem de 10 e $16 \mu \mathrm{m}$, durante 28 dias, nas condições do Norte de Minas.

antado estádio de amadurecimento, induziram os julgadores à rejeição desses frutos. Desse modo, fica evidenciada a eficácia da atmosfera modificada quando corretamente projetada (Mosca et al., 1999) na manutenção da qualidade dos frutos, bem como no prolongamento da vida útil (Kader, 1992).

\section{CONCLUSÃO}

A utilização da atmosfera modificada em bananas permite um período seguro de 28 dias de armazenamento refrigerado com adequada manutenção dos atributos físico-químicos e sensoriais.

\section{REFERÊNCIAS}

Association of Official Analytical Chemists (1992) Official methods of analysis of the Association of Official Analytical Chemists. Washington.
Carvalho HA (1989) Qualidade de banana 'Prata' previamente armazenada em saco de polietileno, amadurecida em ambiente com elevada umidade relativa. Dissertação de Mestrado. Escola Superior de Agricultura de Lavras, Lavras. 92p.

Chitarra MIF \& Chitarra AB (2005) Pós-colheita de Frutos e Hortaliças: Fisiologia e Manuseio.2.ed. Lavras, Universidade Federal de Lavras. 785p.

Codevasf/Emater-MG (2005) Relatório de atividades: projeto Jaíba-Etapa I- agricultura familiar.[s.1.]. Jaíba, Codevasf/ Emater-MG. 54p.

Cordeiro ZJM (2005) Banana. Produção aspectos técnicos. Brasília, Embrapa. 143p Comunicação para Transferência de Tecnologia (Frutas do Brasil, 1).

Dadzie BK \& Orchard JE (1997) Post-harvest criteria and methods for routine screening of banana/plantain hybrids. In: Dadzie BK \& Orchard JE (1997) Routine post-harvest screening of banana/plantain hybrids: criteria and methods. IPGRI, INIBAP ISBN: 2-910810-22-4Technical Guidelines. p.5-14.

Dominguez M \& Vendrell M (1993) Ethylene biosynthesis in banana fruit: Evolution of EFE activity and ACC levels in peel and pulp during ripening. Journal of Horticultural Science, 68:63-70.

Kader AA, Zagoryd D \& Kerber EL (1989) Modified atmosfhere packaging of fruits and vegetables. Food Science and Nutrition, 2:1-30.

Kader A A (1992) Postharvest technology of horticultural crops. California, University California. 296p

Mosca JL, Mugnol MM \& Vieites RL (1999) Atmosfera modificada na pós-colheita de frutas e hortaliças. Botucatu, FEPAF. 28p.

Ledo AS, Silva S de O \& Azevedo FF (1997) Avaliação preliminar de genótipos de banana (Musa spp.) em Rio Branco (Acre). Revista Brasileira de Fruticultura, 19:51-56.

Loesecke HW VON (1980) Banana: chemistry, physiology, technology. 2. ed. New York, Interscience. 189p. (Economic Crops, 1).

Neves LC, Rodrigues AC \& Vieites RL (2002) Polietileno de baixa densidade (PEBD) na conservação pós-colheita de figos cv. "Roxo de Valinos”. Revista Brasileira de Fruticultura, 24:57-62.

Rocha JLV (1984) Fisiologia pós - colheita de banana. In: $1^{\circ}$ Simpósio Brasileiro sobre Bananicultura, Jaboticabal. Anais, Universidade de Ciências Agronômicas e Veterinárias de Jaboticabal. p.353-367.

Rodrigues MGV, Souto RF \& DIAS MSC (2001) B.Manejo do bananal de Prata Anã cultivada no norte de Minas Gerais. In: $1^{\circ}$ Simpósio Norte Mineiro Sobre a Cultura da Bananeira, Nova Porteirinha. Anais, Unimontes. p.154 -167.

Silva SO, Alves EJ, Lima MB \& Silveira JRda. (2002) Bananeira. In: Bruckner $\mathrm{CH}$ (Ed.). Melhoramento de fruteiras tropicais. Viçosa, Universidade Federal de Viçosa. p.101-158.

Silva SO (2006) Cultivares de banana para exportação. In: Silva JMM (Ed.) Banana: produção: aspectos técnicos. Brasília, Embrapa Comunicação para Transferência de Tecnologia, 143p. (Frutas do Brasil, 1).

Souza JP de, Praça EF, Alves RE, Neto FB \& Dantas FF (2002) Influência do armazenamento refrigerado em associação com atmosfera modificada por filmes plásticos na qualidade de mangas “Tommy Atkins". Revista Brasileira de Fruticultura, 24:665-668.

Yamashita F, Miglioranza LHS, Miranda LA |\& Souza CMA (2002) Effects of packaging and temperature on postharvest of atemoya. Revista Brasileira de Fruticultura, 3:658-660. 